\title{
LA FINANCIACIÓN INICIAL Y FINAL EN EL CIRCUITO MONETARIO Y LA TEORÍA DE LA DEMANDA EFECTIVA
}

Sergio Cesaratto*

U na sorprendente característica de la economía heterodoxa moderna es la separación entre los modelos de crecimiento basados en la demanda y las teorías del dinero endógeno. Este trabajo procura llenar ese vacío. Por las razones expuestas en Cesaratto (2015), entre las teorías heterodoxas de la acumulación rivales el artículo recurre al enfoque sraffiano del supermultiplicador (Freitas y Serrano, 2015) ${ }^{1}$, que proporciona un marco prometedor compatible con el legado de grandes maestros heterodoxos, incluidos los economistas clásicos, Marx, Sraffa, Keynes, Kalecki y Kaldor (en adelante, enfoque clásico-keynesiano). El dinero, el crédito y la financiación pueden cumplir un papel importante en este enfoque. Pero, quizá en contra de la tradición de la teoría del circuito monetario (тсM), este enfoque sugiere adoptar en la teoría un lado real robusto dominante y preliminar a un examen coherente del lado monetario. Centrándose en la versión de la тсм de Graziani, este artículo contribuye a reconciliar la

* Profesor del Departamento de Economía Política y Estadística de la Universidad de Siena, Italia, [sergio.cesaratto@unisi.it]. Aunque crítico del circuito monetario, este artículo está dedicado a la memoria del profesor Augusto Graziani. Lamento que mis ideas a este respecto aún no hubiesen madurado en los años noventa cuando tuve la fortuna de colaborar con él en La Sapienza. Él habría apreciado la crítica franca. Agradezco a Eladio Febrero, Fabio Petri, Massimo Pivetti, a varios amigos del Centro Sraffa, en particular a Roberto Ciccone, Sergio Levrero y Saverio Fratini, y a tres árbitros por sus valiosas sugerencias y observaciones. Tomado de Macroeconomica, mayo de 2016. Traducción de Alberto Supelano; se publica con las debidas autorizaciones. Fecha de recepción: 20-062016, fecha de aceptación: 20-10-2016. Sugerencia de citación: Cesaratto, S. "La financiación inicial y final en el circuito monetario y la teoría de la demanda efectiva", Revista de Economía Institucional 18, 35, 2016, pp. 47-78. Dor: http:// dx.doi.org/10.18601/01245996.v18n35.04.

${ }^{1}$ Los autores kaleckianos también prestan creciente atención a este enfoque, p. ej., Allain (2015) y Lavoie (2015a); entre los circuitistas, Eladio Febrero le muestra simpatía (p. ej., Febrero y Bermejo, 2013). 
preocupación de la тсм orientada a la producción con la financiación inicial de la producción, y la preocupación de las teorías heterodoxas del crecimiento orientadas a la demanda con la financiación final de la demanda autónoma, así como a reconocer que el dinero endógeno también es compatible con la teoría marginalista que refuerza la importancia de una contraparte real sólida. Aunque esto se discute más adelante, se debe admitir que si bien el dinero endógeno cumple un papel auxiliar en la teoría neoclásica -útil quizá para explicar fenómenos de desequilibrio, como en los famosos procesos acumulativos wicksellianos de inflación o desinflación-, este papel no es auxiliar en el marco alternativo. En el enfoque clásico-keynesiano no hay un dualismo de largo plazo entre los sectores real y monetario, los cuales representan metafóricamente el esqueleto y el aparato circulatorio, respectivamente, que sirven a los músculos (es decir, al funcionamiento de la economía como un todo) ${ }^{2}$.

La primera sección esboza el enfoque clásico-keynesiano del nivel de producción y crecimiento basado en la demanda y se pregunta cómo encajar la creación de dinero endógeno en ese enfoque, donde los componentes autónomos de la demanda agregada (DA) -que en el corto plazo también incluye la inversión- se consideran como fuerza motriz última del nivel de producción y crecimiento (Cesaratto y Mongiovi, 2015). Aunque rara vez se discute abiertamente, la visión recibida sostiene que la creación de crédito/dinero endógeno financia los pagos finales asociados a estos componentes, es decir, que la demanda monetaria precede a la producción. Pero si las decisiones de producción se toman con base en la demanda esperada o en órdenes de compra, la terminación de la producción precede lógicamente a los pagos por compras. Para cubrir parcial o totalmente los costos de producción (netos de ganancias, que según asumimos solo se materializan mediante las ventas finales) es entonces necesaria una financiación inicial proporcionada por la creación de crédito/dinero endógeno. Como dijo Keynes en 1923:

Durante el largo proceso de producción el mundo empresarial incurre en gastos monetarios - pagos en dinero de salarios y otros gastos de producción- con la esperanza de recuperar esos desembolsos intercambiando el producto por dinero en una fecha posterior (citado por Moore, 1983, 545).

El papel inicial del crédito/dinero endógeno en el arranque de la producción es lo que Keynes llamó “financiación” (1937a y 1937b).

\footnotetext{
2 Es extraño que a François Quesnay, un médico que concibió la economía como un flujo circular de pagos a partir de la circulación de la sangre, no se lo considere un héroe de la TCM.
} 
El papel de la financiación inicial en el arranque de la producción es el área de la тсм que examina la segunda sección, centrándose en los últimos puntos de vista de Augusto Graziani. A veces se citan autores de diferentes tradiciones de la тсм (p. ej., Rochon y Rossi, 2003, Arestis y Sawyers, 2006), cuando comparten puntos de vista y problemas similares, aunque el examen más profundo de sus otras versiones se deja a la investigación futura.

E1 profesor Graziani indicó que los circuitistas se inspiraron en el Tratado del dinero de Keynes (1930) y no en la Teoría general (1936) (Graziani, 1990, 9; 1994, 27). En concordancia, Graziani no asigna un claro papel central a la teoría de la demanda efectiva (DE) en la explicación de las decisiones de producción, y resta importancia al análisis del papel del (super)multiplicador del ingreso para dar una cabal explicación de la interacción entre aspectos financieros y reales, un papel que es precisamente el nexo entre financiación inicial y final. Pasando a las contribuciones de Davidson, Dalziel y otros autores, la tercera sección expone una manera alternativa de integrar la "financiación" de Keynes en el enfoque clásico-keynesiano basado en la demanda. La historia básica es que el crédito/dinero endógeno (financiación inicial) respalda las decisiones de producción basadas en la demanda esperada o en pedidos. Luego el multiplicador del ingreso (o el supermultiplicador) genera los ingresos por medio de los cuales la demanda de consumo esperada y las órdenes de inversión se convierten en gasto efectivo (pagos finales). Como se mostrará, puede ser necesaria una creación de crédito/dinero endógeno final adicional para financiar la inversión deseada y el gasto autónomo. Una vez todo esto se completa, todos los sujetos que recibieron financiación inicial pueden redimir sus deudas, quizá solicitando la renovación de las líneas de crédito para el siguiente periodo de producción. La creación de financiación endógena se asemeja entonces a un fondo rotatorio keynesiano, que crece en una economía en progreso.

Este artículo se puede considerar como un ejercicio de reconciliación entre las teorías que subrayan el papel del crédito/dinero endógeno en la financiación de las decisiones de producción (financiación inicial), como la TCM, y el papel del gasto autónomo como determinante último de esas decisiones, como el análisis del (super) multiplicador. 


\section{ASPECTOS REALES Y MONETARIOS DEL ENFOQUE CLÁSICO- KEYNESIANO}

\section{MULTIPLICADORES}

De acuerdo con el enfoque clásico-keynesiano, los componentes autónomos de la DA -consumo autónomo, gasto del gobierno, exportaciones e inversión de corto plazo- determinan el grado de utilización de la capacidad productiva en el corto plazo y la tasa de crecimiento de la economía en el largo plazo (Cesaratto, 2015; Freitas y Serrano, 2015). Nos referimos específicamente a dos ecuaciones:

1. La primera es la determinación tradicional del producto en el corto plazo a través del multiplicador keynesiano. Los componentes autónomos (consumo autónomo, inversión, gasto público y exportaciones) regulan la DA $\left(Y_{D}\right)$ dada la propensión marginal a consumir c, la tasa de impuestos promedio $t \mathrm{y}$ la propensión marginal a importar $m$ : $\left.Y_{D}=1 \bigwedge 1-c(1-t)+m\right](\bar{C} \bar{a}+\bar{I}+\bar{G}+\bar{E})$

Keynes creía que en las economías capitalistas DA no es en promedio suficiente para utilizar totalmente la capacidad de producción, de modo que el nivel de producción $X$ y el grado de utilización de la capacidad productiva se ajustan al nivel de $Y_{D}$.

2. Sin embargo, en el largo plazo, la capacidad tiende a ajustarse a la DE esperada ${ }^{3}$. En particular, los capitalistas no invertirán a ciegas, sino con base en la DE esperada. Esto se expresa mediante una función de inversión basada en el viejo concepto de acelerador:

$I=v_{n} g^{c} Y_{D}$

en la que $g^{C} Y_{D}$ representa el crecimiento esperado de la DE, y $v_{n}$ es el coeficiente capital-producto, es decir, la cantidad deseada de capital por unidad de producto. Así obtenemos una ecuación similar a la ecuación (1) en la que la fracción se llama supermultiplicador (después de Hicks, 1950):

$\left.Y_{D}=1 \Lambda 1-c(1-t)-v_{n} g^{z}+m\right]\left(\overline{C_{a}}+\bar{G}+\bar{E}\right)=\left[1 / 1-c(1-t)-v_{n} g^{z}+m\right] Z$

donde $\mathrm{Z}$ y $g^{z}$ son el nivel y la tasa de crecimiento de los componentes autónomos de la DA que no crean capacidad, respectivamente, y la inversión es un componente inducido y no autónomo de la DA, como debe ser en un modelo de crecimiento de largo plazo. Suponemos que $g^{z}=g^{e}$. Se puede demostrar que, con supuestos razonables, las tasas de crecimiento real y esperada tienden a ajustarse a la tasa de crecimiento $Z$ (Freitas y Serrano, 2015).

${ }^{3}$ Definida como el volumen de DA futura a precios normales o de largo plazo. 
Supongamos que pasamos de una situación en la que la capacidad de producción es adecuada para la DA. Si se percibe que un aumento de $g^{z}$ es persistente, estimulará la DA incluida la inversión. Normalmente, las firmas tienen ciertos márgenes de capacidad de producción ( $\mathrm{p}$. ej., en cuanto no desean dejar clientes insatisfechos en caso de picos súbitos de demanda). En el corto plazo, esto les permite aumentar la producción de bienes de consumo y de inversión antes de instalar nuevos bienes de capital. Una vez estos empiezan a operar, en el largo plazo la capacidad productiva se ajusta lentamente al nuevo nivel y al crecimiento de la $\mathrm{DA}^{4}$.

Cabe señalar que en este enfoque la inversión no es la variable independiente en la determinación de la DA, como en la mayoría de los modelos de crecimiento postkeynesianos; los componentes autónomos de la DA cumplen el papel de variables independientes, y la inversión es inducida por el mecanismo acelerador ${ }^{5}$. El modelo no recurre entonces a los "espíritus animales" para explicar la inversión, como en la mayoría de los modelos postkeynesianos (ver Cesaratto, 2015, 170).

\section{LA VISIÓN CLÁSICA-KEYNESIANA (IMPLÍCITA) RECIBIDA: EL DINERO ENDÓGENO FINANCIA LA DEMANDA FINAL QUE PRECEDE A LA PRODUCCIÓN}

Es característico del gasto autónomo que no se financia con entradas de ingreso, a diferencia del consumo inducido; por tanto, se debe financiar con creación de crédito ${ }^{6}$. Sorprendentemente, sin embargo, los académicos clásico-keynesianos modernos aún no han explorado plenamente el aspecto financiero de su teoría del nivel de producción y el crecimiento. Aunque no se dice explícitamente, la visión recibida que quizá defienden estos académicos se basa en dos supuestos: 1) la DE real determina la producción y 2) la creación de crédito/dinero endógeno financia el gasto autónomo qua pagos finales efectivos. A

\footnotetext{
${ }^{4}$ La trayectoria "garantizada" que asegura el equilibrio dinámico ahorro-inversión se escribe así: $g_{w}=\left(S / X_{n}\right) / v_{n}$. Esta ecuación sugiere que las variaciones endógenas de la propensión media a ahorrar $S / X_{n}$ acomodan $g_{w}$ a variaciones de $g_{z}$ : la tasa normal se ajusta a la tasa real (Freitas y Serrano, 2015; Cesaratto, 2015, 173-174).

${ }^{5}$ Algunos sraffianos prefieren no formalizar el papel de la demanda autónoma a través del supermultiplicador. Sobre este asunto, Garegnani (2015) es un antecedente común de todo tipo de visiones sraffianas (ver Cesaratto y Mongiovi, 2015).

${ }^{6}$ Como dice Moore: "La tasa a la que se emite [dinero crédito] gobierna la tasa de crecimiento de la demanda agregada. Esta parece una conclusión monetarista. Pero el mecanismo causal nada tiene que ver con un exceso de oferta de saldos monetarios. Resulta simplemente de reconocer que el nuevo dinero crédito financia la mayoría del gasto deficitario neto. En economías monetarias, si la demanda agregada aumenta con el tiempo, en el balance las unidades económicas deben tener algún gasto-déficit" (1988, 291).
} 
través del proceso multiplicador del ingreso, el gasto autónomo genera gasto inducido y ambos generan producción. Esta visión refleja la idea de que la demanda es la que genera la oferta.

En el caso de la inversión, según las ecuaciones (1) y (3) el ahorro es el que se ajusta a la inversión, en el corto plazo a través de la variabilidad del grado de utilización de la capacidad productiva y en el largo plazo a través de los cambios en la capacidad de producción. Aunque en el largo plazo la inversión es un componente inducido de la DA, a diferencia del consumo inducido que se financia con ingresos de los hogares, la inversión no depende ni es financiada con ingreso corriente (aunque es inducida por el ingreso esperado). La visión recibida es que el dinero endógeno financia los pagos efectivos de bienes de inversión (p. ej., Bertocco, 2014, 210 y ss.).

De manera similar, la visión recibida también considera que el gasto de consumo autónomo es financiado normalmente por crédito/dinero creado endógenamente por el sistema bancario (p. ej., ibíd., 211-213) ${ }^{7}$.

La demanda extranjera es financiada por fuentes extranjeras, de modo que es autónoma desde el punto de vista del país exportador. Pero las cosas no son tan simples. El país importador financia sus compras mediante ingresos o mediante la creación nacional de crédito/ dinero endógeno, dentro de los límites de sus reservas extranjeras y del acceso a préstamos extranjeros, salvo que emita una moneda de reserva internacional. El país exportador puede entonces participar como país acreedor (financiando al vendedor). Según la visión recibida, la creación de poder de compra en favor de los compradores del país importador es generada por la creación de dinero/crédito endógeno en los países periféricos seguida por préstamos internacionales de los países del centro (Cesaratto, 2013b, 374-76; Febrero y Uxo, 2013, 3), o directamente mediante la creación de dinero/crédito por los bancos de los países centrales ${ }^{8}$.

7 La literatura reciente subraya el papel del consumo financiado con crédito para sostener la DA en el capitalismo moderno, p. ej., en los años anteriores a la crisis financiera en Estados Unidos, cuando compensó la caída del ingreso de la clase media, pero también originó una crisis financiera (p. ej., Barba y Pivetti, 2009). Un examen crítico del tratamiento neo-kaleckiano del consumo financiado con crédito (p. ej., Hein, 2012) está fuera del alcance de este escrito y queda para la investigación en curso (p. ej., Pariboni, 2015). Basta señalar que el enfoque alternativo del supermultiplicador parece más prometedor porque trata en forma coherente el papel del consumo financiado con crédito como impulsor autónomo de la acumulación.

${ }^{8}$ Como confirmó con autoridad un eminente economista de finanzas internacionales:

En un nivel más profundo, todo esto refleja el fracaso para hacer una distinción suficientemente clara entre ahorro y financiación. Como cuestión de identidades, el ahorro, un concepto de cuentas nacionales, es simplemente ingreso (producto)

Revista de Economía Institucional, vol. i8, n.o 35 , segundo semestre/2oi6, pp. 47-78 
Por último, con respecto al gasto del gobierno, en la lógica keynesiana o kaleckiana el Estado es el que gasta primero, luego recibe ingresos fiscales o emite bonos del tesoro. De hecho, los ingresos fiscales o el ahorro de los hogares (que compran títulos públicos) son un resultado del ingreso generado por el gasto público. El enfoque cartalista (p. ej., Wray, 1998) es interesante a este respecto porque intenta articular las políticas fiscal y monetaria conforme a la lógica keynesiana y kaleckiana. Lavoie (2013), entre otros autores (ver en particular Gnos y Rochon, 2004), es escéptico ante ciertas simplificaciones de los cartalistas - como la consolidación del Tesoro y del banco central (вс) - y propone un mecanismo institucional post-cartalista alternativo más respetuoso de la prohibición, en la mayoría de los marcos institucionales, de que el вс financie directamente al Tesoro. Con algunas reservas, Wray (2011) no rechaza esta visión (el debate se examina en un artículo paralelo: Cesaratto, 2016a).

\section{LA FINANCIACIÓN DE KEYNES: EL DINERO ENDÓgENO FINANCIA LA PRODUCCIÓN QUE PRECEDE A LAS VENTAS}

En suma, según la visión recibida (a menudo implícita) los bancos respaldan el gasto autónomo, los pagos finales efectivos (incluido el gasto del gobierno en la visión cartalista) y la inversión, y la producción sigue al gasto autónomo e inducido. Así es, hasta cierto punto. Sin embargo, en muchos casos prácticos, la producción se inicia en vista de la DE esperada de bienes estandarizados ${ }^{9}$, o de órdenes de compra, por ejemplo, de plantas industriales complejas a la medida del cliente o de bienes de lujo.

no consumido; la financiación, un concepto de flujo de efectivo, es el acceso a poder de compra en forma de un medio de compensación aceptado (dinero), incluso a través de endeudamiento. El gasto de todo tipo, bien sea en activos reales preexistentes o financieros, o en bienes y servicios para fines de inversión o consumo, requiere financiación, no ahorro. En una economía cerrada, el ahorro no es un prerrequisito para la inversión, pero solo se materializa una vez la inversión tiene lugar si se dispone de la financiación necesaria. En una economía abierta, por construcción, un déficit en cuenta corriente en alguna parte debe ser compensado por un excedente en alguna otra parte. Pero los países con superávits en cuenta corriente no financian a los que tienen déficits en cuenta corriente. Los gastos de consumo y de inversión subyacentes que generan esas posiciones pueden ser financiados de numerosas maneras, doméstica y externamente (Borio, 2014, 13, cursivas añadidas).

${ }^{9}$ La competencia entre productores listos a servir a clientes puede llevarlos a preparar producción con antelación, en especial cuando toma tiempo (incluida la entrega) y en particular en la manufactura. A la inversa, muchos servicios, como cortes de pelo, masajes, exámenes médicos o asistencia técnica, son proporcionados de inmediato. 
Esto asignaría a los bancos un papel adicional -llamémoslo "financiación inicial"- en la financiación de la producción durante el periodo de gestación de la producción, es decir, entre el periodo en que toman forma las expectativas o pedidos y el de entrega de los bienes y pagos finales ${ }^{10}$. Una dificultad adicional de la visión recibida es que, especialmente en algunos contextos institucionales, ese gasto de inversión no es financiado por los bancos que crean dinero endógeno sino por instituciones que crean dinero no endógeno, como los bancos de inversión, las bolsas de valores o utilidades retenidas.

Es sabido que Keynes se refirió al papel de la "financiación inicial" con el término más breve "financiación" (1937a y 1937b), definida como "la financiación requerida durante el interregno entre la intención de invertir y su realización", "proporcionada principalmente por especialistas, en particular por los bancos", que anticipan efectivo (1937b, 219). Keynes especifica que "la financiación de la inversión es, por supuesto, solo un caso especial de la financiación requerida por cualquier proceso productivo" $(1937 \mathrm{a}, 208)$ incluida la producción de bienes de consumo con antelación a la demanda de consumo (aunque la mayor parte del debate se ha centrado en la financiación de la inversión $)^{11}$. Tomando el caso de la financiación de la inversión, si la inversión es constante, la financiación será un "fondo rotatorio" más o menos constante: "un empresario obtiene su financiación para proyectos de inversión a medida que otro agota la suya al ir pagando sus inversiones realizadas"(1937a,209). Si la inversión está aumentando, el efectivo adicional se podría obtener, por ejemplo, mediante sobregiros no utilizados $(1937 \mathrm{~b}, 223)$ o, por supuesto, mediante "financiación adicional” (1937a, 209). Cabe señalar que la financiación inicial no solo atañe a las líneas de crédito/dinero endógeno de los bancos a los productores, sino también a los anticipos de los compradores, como las garantías de los pedidos.

10 "En las economías modernas normalmente se incurre en costos de producción que se pagan antes de recibir ingresos por ventas. Esos costos representan una inversión en capital de trabajo, para la cual necesariamente se debe obtener financiación" (Moore, 1983, 545-546). En principio, la producción se podría emprender pagando los salarios y otros costos después de las ventas. Pero dependiendo de la longitud del proceso de producción, en muchos casos los salarios y otros costos se deben pagar, en parte o en su totalidad, antes de las ventas. Esto no significa que los salarios se anticipen totalmente al comienzo del proceso de producción, como suponen en general los exponentes de la тсм. Sea como fuere, en este escrito asumimos que las ganancias se realizan a través de las ventas reales.

${ }^{11}$ En su polémica con Ohlin, quien apoyaba la noción espuria de "ahorro ex ante", Keynes $(1937 b, 221)$ argumentó con un toque de ironía que la producción de bienes de consumo no necesita ser financiada por "consumo ex ante" así como no se requiere "ahorro ex ante" para realizar la inversión (de hecho, ambas son financiadas con creación de dinero endógeno). 
¿E1 papel de la creación de crédito/dinero endógeno en la financiación de la oferta con base en expectativas o en pedidos contradice el principio de la DE? Es decir, ¿no tiene el riesgo de restaurar implícitamente la ley de Say de que la oferta crea la demanda? De ningún modo, como sugiere el diagrama estándar de la cruz keynesiana, donde la oferta agregada (OA) (las decisiones de producción) se representa en el eje vertical y la DA en el eje horizontal. Los puntos de equilibrio macroeconómico entre DA y OA se sitúan en la bisectriz. Para cada decisión de producción y el ingreso distribuido relacionado, la función keynesiana DE indica el nivel correspondiente de DA. Las decisiones de producción se ajustan a DA hasta el punto donde OA genera una cantidad equivalente de DA.

Nuestro problema es ahora integrar la financiación inicial concerniente a la producción y la visión recibida explicada anteriormente -que se centra en la financiación final concerniente al gasto- en una síntesis más abarcadora de los factores reales y monetarios de la teoría de la producción y el crecimiento. Luego será natural trasladar la atención a la тсм que subraya el papel del crédito/dinero endógeno en la financiación de la producción y no en la demanda final. Pero antes comparemos brevemente la visión del dinero endógeno -bien se refiera a la financiación de la producción o a los pagos finales (o a ambos, como veremos)- con la visión convencional.

\section{EL DINERO ENDÓGENO Y LA TEORÍA MARGINALISTA}

De acuerdo con la visión del dinero endógeno ${ }^{12}$, los bancos pueden crear depósitos - p. ej., en forma de sobregiros- en favor de inversionistas confiables mientras que el вС ajusta la oferta de reservas, al menos en cuanto desee estabilizar la política de meta de tasa de interés. En esta visión "los préstamos crean depósitos y los depósitos crean reservas".

En su versión más rígida, la visión convencional de los marginalistas y los keynesianos afirma que la cantidad de dinero (la oferta de reservas) es determinada exógenamente por la autoridad monetaria (Terzi, 2012, 9). Controlando la cantidad de dinero de alta potencia (reservas), la autoridad monetaria determina la tasa de interés que se debería fijar en su nivel natural (wickselliano), para obtener el equilibrio de pleno empleo. Una visión tradicional de la banca sostendría entonces que los "fondos prestables" son los que financian la inversión, donde los "fondos prestables" son los ahorros de pleno empleo recaudados por los bancos (p. ej., Febrero, 2001, 4-5). Las

${ }^{12}$ Para una introducción, ver Lavoie (2005). 
autoridades monetarias deben entonces afinar la tasa de interés monetaria para que los fondos prestables se ajusten a la inversión con la tasa de interés natural, la cual iguala la capacidad-ahorro de pleno empleo y la inversión.

Sin embargo, un economista tradicional de mente flexible no estaría de acuerdo con esa visión. De hecho, siguiendo a Wicksell (1935, 194), apoyaría la idea de que los préstamos crean depósitos (Pivetti, 2001, 104-105). Es decir, puede admitir que los "fondos prestables" no son el resultado del recaudo de ahorros ex ante por los bancos sino de la creación de poder de compra por los bancos. De manera similar, en la macroeconomía convencional reciente la cantidad de dinero es endógena en el sentido de que el вс primero fija la tasa de interés (intentando acercarla al nivel natural), y dada la demanda de dinero, deja que la oferta monetaria (endógena) se ajuste para obtener la tasa objetivo ${ }^{13}$. La sustancia no es, sin embargo, diferente de la del enfoque del dinero exógeno: se presta atención a la tasa de interés natural, la tasa a la cual la inversión es igual a la capacidad-ahorro de pleno empleo (Bougrine y Seccareccia, 2004) ${ }^{14}$.

La diferencia real entre economistas keynesianos auténticos y economistas tradicionales es que según estos últimos el nivel de inversión tiende a adecuarse a la capacidad-ahorros de pleno empleo, al menos en la medida en que la tasa de interés a la cual prestan los bancos-que depende de la tasa objetivo fijada por la política monetaria- sea la tasa de interés natural wickselliana. Los economistas tradicionales están dispuestos a admitir que el dinero endógeno es el que financia la inversión, la que a su vez genera ahorros. En su visión esto se puede hacer a una tasa de interés en la cual la inversión genera capacidad-ahorros de pleno empleo ${ }^{15}$. La sustancia no es entonces diferente del enfoque del dinero exógeno: se presta atención a la tasa de interés natural, la tasa a la cual las inversiones son iguales a la capacidad-ahorros de pleno empleo. Es necesario tener esto en cuenta porque muestra que la endogeneidad del dinero - la cual es un hecho reconocido fuera de la economía heterodoxa tradicional; p. ej., por banqueros centrales, como los economistas del всг Bindseil у Konig (2013) о el Banco de

\footnotetext{
${ }^{13}$ Jakab y Kumhof (2015), p. ej., exploran el dinero endógeno en modelos DSGE.

${ }^{14}$ Por supuesto, los BC no conocen la tasa de interés natural. Se supone entonces que la aproximan cuando el desempleo está en su nivel "natural", es decir, de modo que mantenga a raya las demandas de mejoras salariales $y$, en consecuencia, la inflación cerca a cero o constante.

${ }_{15}$ Como dijo Graziani: "una economía monetaria, siempre que esté dotada de un sistema bancario capaz de operar correctamente, puede asegurar un equilibrio sustancialmente idéntico al de una economía de trueque [neoclásica] caracterizada por precios monetarios estables" $(1994,45)$.
} 
Inglaterra (McLeay et al., 2014) - no es una crítica suficiente de la teoría neoclásica ni, por tanto, una premisa adecuada para una teoría monetaria heterodoxa de la producción y la acumulación ${ }^{16}$. Esto no niega que el dinero endógeno cumple un papel más esencial en un contexto heterodoxo, solo argumenta que el esqueleto importa y no únicamente la circulación de la sangre. Los economistas tradicionales y heterodoxos pueden compartir la visión del dinero endógeno, pero no comparten la descripción real de la economía, la cual es por tanto una prioridad en el análisis.

También se puede adoptar una imagen flexible de la visión tradicional en el caso del consumo autónomo, las exportaciones e incluso el gasto del gobierno (ver Cesaratto, 2016a). El consumo autónomo se puede entender, por ejemplo, como un fenómeno de equilibrio en el que existen hogares racionales heterogéneos en diferentes etapas del ciclo biológico, de modo que los hogares ahorrativos prestan recursos a hogares temporalmente derrochadores a una tasa de interés de equilibrio. Bien podemos pensar que este es crédito/dinero creado endógenamente que financia a las unidades derrochadoras, y que los ahorros de las unidades parsimoniosas son generados por el proceso multiplicador del ingreso.

Así mismo, aunque la versión rígida de la teoría neoclásica interprete los flujos internacionales de capital como flujos de ahorro de los países ricos en capital hacia países pobres en capital -una extensión de la teoría de los fondos prestables a la economía abierta-, son posibles interpretaciones más flexibles. Se podría argumentar que para los economistas neoclásicos los flujos de capital son también, en primer lugar, el resultado de la creación de crédito endógeno (Cesaratto, 2013b, 374-376). Este gasto genera un déficit en cuenta corriente que ahora corresponde a préstamos respaldados por ahorros de países exportadores más ricos. Este se ve como un proceso de equilibrio a

\footnotetext{
16 Tan adecuada, por ejemplo, como la crítica a la teoría del capital que realmente se refiere a la parte real de la teoría neoclásica (para una reconstrucción rigurosa de la controversia de la teoría del capital, ver Lazzarini, 2011). John Smithin argumenta que "aun sin la intervención de los debates muy técnicos de la teoría del capital" $(2009,80)$, el enfoque de Wicksell es un "híbrido 'espurio' de la teoría clásica [marginalista] y la teoría horizontalista” (ibíd., 86); a pesar de su mayor realismo aparente y de los “orígenes wicksellianos" de la teoría monetaria convencional moderna (ibíd., 85). En particular, denuncia la estimación de la tasa de interés natural basada en una "teoría particular de la inflación" (ibíd., 86), como se indica en la nota 14. En mi opinión, esta posición traslada la crítica de la teoría del capital a la crítica de la tasa de interés natural. De hecho, la "teoría particular de la inflación" a la que se refiere Smithin se basa en la teoría marginalista de la distribución.
} 
través del cual en todo el mundo se iguala la intensidad de capital per cápita de las técnicas y. por tanto, los ingresos per cápita ${ }^{17}$.

\section{LA “FINANCIACIÓN"Y EL CIRCUITO MONETARIO}

\section{EL CIRCUITO Y SUS PROBLEMAS}

La тсм destaca el papel del sector financiero en la ignición del circuito económico. Hace énfasis en el lado de la producción, es decir, en el papel de la creación de crédito/dinero endógeno en la financiación de los costos de producción (principalmente de los costos de salarios). E1 resumen de las fases del circuito tomado de Realfonzo (2006, 106107) es suficientemente representativo (ver también Lavoie, 1992, 152-157; Graziani, 2003, 26-31):

1. Los bancos otorgan [...] la financiación solicitada a las firmas, creando dinero (apertura del circuito);

2. Una vez obtienen la financiación, las firmas compran insumos. Considerándolas en conjunto, su único gasto coincide con la nómina total; en este punto el dinero pasa de las firmas a los trabajadores;

3. Una vez compran los servicios de trabajo, las firmas llevan a cabo la producción $[\ldots]$

4. Al final del proceso de producción, colocan los bienes en el mercado. Suponiendo que los trabajadores tienen una propensión a consumir igual a 1 , las firmas recuperan la nómina total y mantienen la propiedad de una parte de los bienes producidos (correspondiente al margen sobre el costo). Si la propensión a consumir es menor que uno, [...] los trabajadores deben elegir además cómo usar sus ahorros, bien sea atesorarlos (aumento de reservas en efectivo) o invertirlos (compra de acciones). Si todos los ahorros en dinero se invierten en acciones en el mercado financiero, las firmas logran recuperar la nómina total;

5. Una vez se han vendido los bienes y las acciones, las firmas pagan a los bancos (cierre del circuito).

Examinemos ahora las preguntas más evidentes que suscita el circuito.

\section{PRoblemas de LA TCM}

\section{Realización de las ganancias en el circuito}

El problema más discutido es el de la realización de las ganancias: si los bancos solo financian los costos de salarios, de modo que la DA solo proviene de los salarios (fase 2), ¿cómo se puede vender la producción (fase 4) a un precio que también incluye las ganancias de las firmas y

${ }^{17} \mathrm{La}$ relación causal marginalista de mercado abierto entre ahorro e inversión en que se basa esta visión es también el tema de la crítica de la teoría del capital (Cesaratto, 2013a, 254). Para una crítica keynesiana de la visión convencional de los flujos internacionales de capital, ver Dalziel y Harcourt (1997). 
los pagos de intereses a los bancos? Con respecto a la generalidad de las tradiciones de la тсм, Febrero resumió bien el problema:

Este enfoque describe en forma coherente cómo el dinero pone en marcha las ruedas de la producción. Pero tiene algunos problemas. Uno de ellos [su "dificultad principal"] es cómo se realizan las ganancias en dinero. Este problema se puede describir así: los bancos crean dinero para financiar los costos de producción de las firmas, a fin de iniciar nuevos procesos de producción. Se supone que esa liquidez se mantiene dentro de la economía hasta que finalizan los procesos de producción y las firmas endeudadas la recuperan con la venta de su producto o, alternativamente, mediante la emisión de activos en los mercados financieros. ¿Si la máxima cantidad de dinero que pueden conseguir se limita a los costos de producción, cómo se pueden monetizar las ganancias (y el interés de las deudas)? (Febrero, 2008, 111).

Aún no parece haber surgido una respuesta compartida, sencilla y, por ello, creíble. Un conocido circuitista concluyó: "quizá no se pueda llegar a conclusiones satisfactorias” (Rochon, 1999, 17) ${ }^{18}$.

\section{Ahorros y pérdidas de los capitalistas}

Como vimos, en la fase 4 del circuito, si los ahorros de los trabajadores "se invierten en acciones en el mercado financiero, las firmas logran recuperar todos los salarios" y "pagar a los bancos". A este respecto Graziani sostiene: "solo hay un evento que puede causar pérdidas a las firmas, la decisión de los ahorradores de no gastar parte de sus ingresos y atesorarla, en cambio, como saldos líquidos" (1994, 79). Sin embargo, en la medida en que los ahorros se colocan en los mercados financieros, las firmas pueden emitir bonos y "recuperar la liquidez

${ }^{18}$ Las soluciones propuestas por académicos de diversas tradiciones de la TCM incluyen diversos argumentos (ver Rochon, 2005, 130-133; Febrero, 2008, 116-117). Para dar unos pocos ejemplos, a pesar de la importancia atribuida al dinero, las firmas retendrían ganancias en especie, como en el punto 4 de la descripción del circuito de Realfonzo. Del mismo modo, Graziani (2003, 31) argumenta que las firmas pagan intereses en especie a los bancos, compartiendo parte del producto con ellos. También sostiene que si las firmas consideradas como un todo integral "pretenden emplear directamente parte del producto, lo retienen sin venderlo" (1994, 105), como si la producción consistiera en un solo capitalista (bancos consolidados y firmas no bancarias) que consume directamente el excedente social. Es sorprendente que en una teoría del circuito monetario esta solo incluya pagos y gastos de salarios. De acuerdo con otra visión, los bancos financian los pagos de intereses y de dividendos (Lavoie, 1992, 152). La idea de que los intereses y los dividendos no se pagan mediante ingresos sino mediante deuda parece peculiar, al menos en el largo plazo. En otros pasajes Graziani (1994, 30, 106, $149 ; 2003,98-100)$ argumenta que los bancos financian las compras de bienes de capital de las firmas, un gasto que lleva a la formación de ganancias; quizá a través del mecanismo kaleckiano por medio del cual los capitalistas ganan lo que gastan. Infortunada e inconsistentemente, Graziani también argumenta que "la financiación de la inversión [...] nada tiene que ver con la financiación bancaria" $(1994,81 ; 2003,73)$ sino que depende de los ahorros. El lector se queda entonces confundido. 
de esta manera" (ibíd.) y pagar sus deudas. Esta visión también está presente en otras tradiciones de la тсM. Rochon (1999, 15), por ejemplo, la expresa así:

La decisión de los hogares de atesorar parte de sus ahorros ciertamente constituye un drenaje de las ganancias de la firma. Después de todo, es el dinero que las firmas no pudieron recuperar a través del consumo o del mercado financiero. Esta cantidad representa la deuda pendiente de las firmas. En este punto, los bancos se convierten en intermediarios financieros, que reúnen los ahorros de los hogares y los prestan de nuevo a las firmas, lo que les permite refinanciar sus posiciones de déficit [...] Esta visión es compartida por muchos circuitistas [...] Las crisis se pueden evitar en la medida en que los bancos puedan ejercer esta función.

Esta idea de que los ahorros de los trabajadores o de las familias se pueden usar para subsanar las pérdidas de las firmas y evitar crisis parece problemática, al menos en el largo plazo ${ }^{19}$. La acumulación de deuda de las firmas no es un problema para los circuitistas porque en cualquier periodo los bancos refinancian el pago de intereses de esta deuda "perpetua" (Lavoie, 1992, 156; Rochon, 1999, 13, 2005, 130-131). Esta sorprendente resiliencia del producto ante la caída de la DA nos indica la necesidad de una integración más completa de la teoría de la DE de largo plazo en la тсм.

\section{Decisiones de producción y demanda agregada}

Aunque la mayoría de los circuitistas de tradición italiana y de otras tradiciones argumentan que las decisiones de producción se basan en la DA esperada (p. ej., Rochon, 1999, 7; 2003, 125; 2006, 127; Realfonzo, 2006, 112, 114), la teoría del crecimiento basada en la

19 "Las firmas necesitan captar ahorros de las familias emitiendo títulos [...] Los fondos retornarán a las firmas para pagar su deuda" (Rochon, 2005, 136). Esa misma posición se expresa en Lavoie (1992, 154-161), Rochon (2003, 129 y n. 19; 2005, 130), Gnos (2006, 91) y Febrero (2001, 11-12). En la práctica, el ahorro de los trabajadores es compensado por el desahorro (pérdidas) de los capitalistas. Alternativamente, podemos pensar que el producto no vendido se almacena como inventarios (indeseados). En este caso las pérdidas se consideran como inventarios y los ahorros de las familias corresponden a inversión en inventarios. Sea como fuere, estos son casos de muy corto plazo y es difícil creer que en un periodo más largo las firmas emitan acciones para financiar pérdidas o una acumulación prolongada e indeseada de inventarios. Esa cuestión recuerda una discusión sobre el Tratado (1930) entre Dennis Robertson y Keynes acerca de la idea keynesiana de que los ahorros de los trabajadores pudieran cubrir las pérdidas de las firmas (Cesaratto, 2016b). En esa discusión Robertson negó que los ahorros pudiesen corresponder a las pérdidas de las firmas, argumentando que los ahorros no existen independientemente de la inversión. Los circuitistas parecen reiterar el error del Tratado de sostener que parte de los ahorros corresponde a pérdidas de las firmas y que se les prestan a las firmas para subsanarlas (Graziani, 1994, 153-154; 2003, 154-155), mientras que ignoran los efectos de esas pérdidas sobre el producto, como señaló Robertson a comienzos de los años treinta. 
demanda no está suficientemente integrada a la тсм. En particular, Graziani $(1994,2003)$ guarda silencio a este respecto. Esto sugiere que su enfoque corresponde a una visión de la demanda anterior a la Teoría general que destaca las decisiones de producción y no modela la DA; olvidando que la financiación de Keynes proviene de la Teoría general y no del Tratado. De hecho, no es cierto que las firmas "tengan total independencia cuando deciden acerca de los aspectos reales de la producción, es decir, de los niveles de empleo y de la cantidad de bienes de consumo y de bienes de inversión producidos", como sugiere Graziani $(2003,29)$, porque las decisiones de producción dependen del nivel y de la composición de la DA. Aun así, él explicaría las crisis por las decisiones unilaterales e inexplicadas de las firmas para reducir la producción: "una decisión autónoma de las firmas de reducir los niveles de actividad" $(1994,155 ; 2003,156)$. En otros pasajes, Graziani alude al poder que el acceso irrestricto al crédito bancario otorga a los capitalistas para decidir la proporción del producto total consistente en bienes de capital (p. ej., 1994, 77; 2003, 73, 98-99) ${ }^{20}$.

En contra de la opinión de Graziani de que "el nivel de empleo [...] es determinado por decisiones tomadas en conjunto por los bancos y las firmas" $(1990,8)$, las firmas no son autónomas para decidir el nivel y la composición de la producción porque sus decisiones dependen de la demanda esperada (expectativas que los bancos deben compartir, por supuesto, cuando otorgan un crédito). Como explica Bertocco:

La principal limitación de este enfoque [de la тсм] es que ignora el principio keynesiano de la demanda efectiva; el nivel y la composición del ingreso están de hecho determinados al principio del periodo por las decisiones de las firmas acerca del número de trabajadores que van a emplear en la producción de bienes de inversión y de consumo (2005, 495-496).

Por ejemplo, dado el nivel y la composición de gasto autónomo (z), el supermultiplicador determinaría el nivel y las proporciones relativas de $Z, C$ e $I$ (y los requerimientos directos e indirectos de insumos correspondientes). Haciendo eco a Kalecki, los capitalistas hacen muchas cosas como clase, pero no planean la producción como clase. Argumentar lo contrario sería un desliz peligroso en alguna especie de ley de Say, algo que quizá no sea lo que la mayoría de los circuitistas tiene en mente.

En un tono más positivo, aunque la тсм de Graziani no llegue a ser una "teoría monetaria de la producción" keynesiana auto consistente (en el sentido de la Teoría general), la relevancia que atribuye a la

${ }^{20}$ Hay semejanza con el enfoque de la "ecuación de Cambridge" en que los capitalistas pueden obtener la cantidad de bienes de capital que deseen. Para la crítica kaleckiana y sraffiana de la ecuación de Cambridge, ver Cesaratto (2015). 
financiación inicial es no obstante importante y se debería incluir en la teoría del producto basada en la demanda ${ }^{21}$. Recurramos entonces a algunas ideas de Davidson (1986), quien propone una integración prometedora y ordenada de la financiación inicial de la producción y la financiación final de los pagos, en la cual el nexo es precisamente el análisis del multiplicador del ingreso.

\section{EL CIRCUITO MULTIPLICADOR MONETARIO-PRODUCCIÓN}

\section{FINANCIACIÓN INICIAL Y FINAL}

Davidson distingue entre "la financiación necesaria de un proyecto de inversión mientras se está construyendo (de corto plazo) y el $f$ nanciamiento [funding] de un proyecto de inversión después de que es completado (de largo plazo)" (1986, 1; cursivas añadidas). Las decisiones de inversión suelen involucrar los siguientes pasos ${ }^{22}$ :

1. Una vez decidida la inversión, "la firma normalmente contratará a un asegurador (banquero de inversión), que comprometerá contractualmente a su entidad a proporcionar la flotación de una nueva emisión, a una tasa de interés de largo plazo específica [...] Se espera que los ingresos por la venta de la nueva emisión generen un 'fondo de inversión' para que el comprador [del bien de capital] pague al vendedor [del bien de capital] en la fecha de entrega. [...] Armado con la garantía del asegurador de proporcionar liquidez mediante el 'fondo de inversión' [...] el empresario inversionista puede hacer con seguridad un pedido a futuro y hacer un contrato de venta con el productor de bienes de capital" (ibíd., 103, cursivas añadidas). Suponemos que la firma inversionista (el comprador del bien de capital) desea financiar el precio total $P_{k}$ del bien de inversión.

2. "Normalmente, el productor de bienes de capital es un cliente confiable de un banquero comercial. Por ello, el contrato de orden de compra firmado suele ser una garantía más que suficiente para que ese banquero esté dispuesto a comprometer al banco a financiar los

\footnotetext{
${ }^{21}$ Un artículo de Fontana y Sawyer (2016) combina la тсм y un modelo kaleckiano basado en la demanda. Pero el vínculo entre los dos aspectos no está articulado sino consignado en una nota de pie de página, donde simplemente observa que "los teóricos del circuito monetario prefieren hablar de financiación de planes de producción (de bienes de consumo y de capital) y no de financiación de la inversión, donde este último término se usa para indicar la compra de bienes de capital. Para los fines de este artículo, financiación de la producción y financiación de la inversión se consideran sinónimos" (n. 9). El presente escrito intenta integrar plenamente la financiación de la producción y la financiación de la inversión.

${ }^{22}$ Se pueden encontrar historias similares en Wray $(1991,957-958,962)$, Dalziel (1996, 314-318), Chick (2000, 124-127) y Bossone (2001, 861).
} 
costos de producción del productor (capital de trabajo) con un préstamo de corto plazo durante la duración del periodo de producción” (ibíd., 103-104). Podemos suponer que el banco financiará los costos de producción $P_{c}$ del bien de capital, incluido el pago de intereses del préstamo pero netos de las ganancias normales proyectadas por el proveedor del bien de capital. Así, esperamos que $P_{c}<P_{k}$.

3. "El solo hecho de que unos recursos antes ociosos ahora estén produciendo bienes de inversión reales [...] significa que, debido al aumento del flujo de ingresos, debe ocurrir pari passu un mayor flujo de ahorro efectivo". El ahorro, por supuesto, proviene de la operación del multiplicador keynesiano del ingreso (Dalziel, 1996). A diferencia del enfoque de la тсM, aquí las decisiones de producción se toman con base en la demanda: un pedido, en el caso del productor de bienes de capital, o la demanda de bienes de consumo inducida resultante de la operación del multiplicador del ingreso, en el caso de la oferta de bienes de consumo.

4. Los ahorros se usan eventualmente para financiar la compra final de bienes de capital: "Estos ahorros reales están muy dispersos entre los hogares y otros agentes que han recibido ingresos en este periodo pero no han ejercido todos los derechos sobre los productos de la industria que les proporciona su ingreso. En una economía monetaria, estos derechos no ejercidos inicialmente toman la forma de posesión de dinero líquido. Cuando la inversión real se ha producido y los flujos reales de gasto asociados se han completado, el asegurador de la inversión puede flotar la nueva emisión, cuyo valor nominal es igual al precio de compra de la nueva inversión. Si el asegurador logra flotar la emisión a la tasa de interés mencionada en el contrato de aseguramiento como costo de financiamiento, el asegurador obtiene una ganancia. A la tasa de interés de largo plazo, el público habrá renunciado a sus derechos actuales (líquidos) sobre los recursos en un monto igual al de la liquidez adicional creada por el sistema bancario y utilizada por el productor de bienes de capital para cumplir sus compromisos de pago de costos de producción" (ibíd., 105)

${ }^{23}$ Refiriéndose a esta secuencia (con algunas variaciones), Febrero $(2008,118)$ también la atribuye a Graziani: "Aunque algunos autores heterodoxos aceptan que la inversión es al menos en parte financiada por crédito bancario" (incluidos Parguez, Rochon y Seccareccia), otros (incluidos Davidson y Graziani) "afirman que los costos de producción de capital fijo proporcionan al sistema liquidez para financiar su compra después de la producción. Este argumento se conoce como 'fondo rotatorio de financiación' y se puede sintetizar así. Una firma espera un aumento de la demanda de su producto en el futuro cercano; naturalmente deseará adaptar su capacidad de producción al nivel necesario para satisfacer esta demanda. Llega a un acuerdo con el productor de capital fijo. El mismo contrato es utilizado como garantía por este último para conseguir financiación 
Davidson cuenta la misma historia con algunas variaciones. Por ejemplo, los bancos financian al productor de bienes de capital, pero también los pagos anticipados de la compañía inversionista (el comprador). "Durante el periodo de gestación de la producción del bien de capital" -argumenta Davidson- "los pagos parciales provisionales de los compradores de sus préstamos bancarios de corto plazo más la financiación del capital de trabajo que se obtiene al menos en parte mediante préstamos de corto plazo de los bancos a los productores de bienes de capital son utilizados por estas firmas productoras para pagar salarios y materias primas" $(1978,323)$. Igual que en la historia anterior, las firmas inversionistas eventualmente pedirán prestados a largo plazo los ahorros generados por el proceso multiplicador del ingreso. Estos ingresos luego son usados por la compañía inversionista "para completar los pagos a los proveedores" y "cancelar el crédito provisional de corto plazo".

\section{Salvedades}

Aunque es un paso adelante, en esta secuencia aún subsisten varios problemas.

1. Las características institucionales de la historia pueden variar según las regiones específicas, por ejemplo, entre la manera de fresca y comprar el capital de trabajo requerido para la producción de los bienes de inversión en cuestión. A esta, Graziani [...] la llama 'financiación inicial' y es de corto plazo. Una vez se producen los bienes, la liquidez se mantiene en el sistema. Si la preferencia de liquidez es nula, el comprador de los bienes de inversión emitirá bonos o acciones ordinarias para captar esta liquidez y financiar la compra de capital fijo en el largo plazo. Los ingresos de la venta de títulos son financiación final, en la terminología de Graziani”. Es cierto que Graziani distingue entre financiación inicial o transitoria y financiación final (p. ej., 1994, 80-84; 2003, 69-74) argumentando que la primera es financiada por los bancos y la última por los ahorros ("que nada tienen que ver con la financiación bancaria", ibíd., 81). Pero no describe con suficiente claridad un proceso à la Davidson (a quien no cita en 1994 ni en 2003). Si lo hubiese descrito claramente habría entendido que el crédito bancario inicial es el que genera los ahorros y, por tanto, la financiación final, como muestra un importante artículo de Dalziel (1996, 314-320). Además, al lector de Graziani le queda confuso el destino de los ahorros para cubrir las pérdidas de las firmas, discutido más atrás, y el de la financiación de la inversión. De nuevo, la falta de un esqueleto real consistente en un análisis del multiplicador (o del supermultiplicador) hace vago el análisis. De modo similar, Passarella y Sawyer consideran el circuito como algo referido a la financiación inicial y final: "Para que se emprenda la inversión, se debe financiar la compra de los bienes de inversión, y se debe financiar el proceso de producción por medio del cual se producen los bienes de inversión”. Sin embargo, el mecanismo de coordinación entre financiación inicial y final no va más allá de unas vagas líneas tradicionales: "En el circuito simple [...] mientras que los bancos comerciales proporcionan financiación inicial, el sistema financiero fue representado en términos de la financiación final mediante la cual las firmas vendieron activos financieros a las familias" (2014, pp. no numeradas). 
proporcionar financiación final centrada en el mercado financiero (financiamiento de largo plazo) de Estados Unidos y la estructura de financiación del modelo europeo, que se basa más en los bancos. Aunque puede ser conveniente investigar más en esta dirección, la distinción entre intermediarios financieros bancarios y no bancarios -que pueden ser dos departamentos distintos, uno monetario y uno financiero, del mismo banco- (expuesta por Bossone, 2001, n. 12), es suficiente para el propósito actual:

a. Los bancos operan río arriba en el proceso del circuito. Permiten iniciar el circuito proporcionando liquidez a la producción. Esta liquidez tiene la forma de obligaciones propias de los bancos, o de documentos de deuda girados sobre los bancos, que se ponen a disposición de los prestatarios. Los bancos no intermedian la liquidez existente sino que añaden liquidez al sistema cada vez que otorgan un nuevo crédito a las firmas mediante creación de depósitos, mientras que al mismo tiempo mantienen la plena liquidez de las reclamaciones de los depositantes [...]

b. Las entidades no bancarias operan aguas abajo en el proceso. Actúan como intermediarios del mercado de capitales con horizontes de tiempo más largos que los bancos, recogen la liquidez existente (depósitos bancarios) de los ahorradores con posiciones largas (que en este caso hace parte de la liquidez), y la asignan a los inversionistas con posiciones cortas (ibíd., 869).

En suma, los bancos tienen que ver con la financiación (o financiación inicial) mientras que los intermediarios no bancarios tienen que ver con el financiamiento (financiación final) ${ }^{24}$.

Febrero $(2008,118)$ señala un problema relacionado con respecto al caso de preferencias de liquidez positivas de los hogares (hogares que no desean prestar a largo plazo). Sugiere que en este caso los bancos intermediarán depósitos a la vista como financiación final, lo que es posible en Europa. Considerando el caso estadounidense, Davidson examina qué sucede si "a la tasa de interés inicial algunos hogares desean mantener parte de sus ahorros en forma de dinero totalmente líquido" $(1986,109)$. En ese caso, aunque los ahorros correspondan en principio a la financiación final (inversión), solo una tasa de interés más alta los puede inducir a desprenderse de liquidez, salvo que el вС, para mantener las tasas objetivo, absorba títulos de largo plazo.

2. Febrero alude a un problema más urgente cuando argumenta que al final de la secuencia davidsoniana "el equilibrio requiere que la financiación inicial cubra totalmente la financiación final” (ibíd., 118). Como suele ocurrir, la financiación inicial solo cubre los costos de producción de los bienes de inversión netos de ganancias y no su

${ }^{24}$ En un línea similar: "La 'característica creación de dinero de los bancos no es solo esencial para entender las operaciones del sistema financiero', también significa que el papel de los bancos y el papel de los mercados [financieros 'no bancarios'] no son comparables" (Sawyer 2014, pp. no numeradas). 
precio total, $P_{c}<P_{k}$, como ya se indicó. En consecuencia, los ahorros generados por el proceso multiplicador después de la producción del bien de capital, y canalizados como financiación final de largo plazo a la firma inversionista a través de intermediarios financieros no bancarios, son menores que los fondos finales necesarios que se deben recaudar ${ }^{25}$. El acertijo de la тсM relacionado con el hecho de que las ganancias no se incluyen en la financiación inicial resurge de nuevo, aunque en otro contexto ${ }^{26}$.

No hay otra solución que suponer que las entidades "no bancarias" financian de algún modo todos los pagos finales de los bienes de inversión $\left(P_{k}\right)$, en parte intermediando ahorros generados por el proceso davidsoniano (igual a $P_{c}$ ) y en parte recurriendo a la creación de nuevos depósitos de corto plazo $\left(P_{k}-P_{c}\right)^{27}$. Esto podría tomar la forma de un préstamo a corto plazo del departamento monetario al financiero del mismo banco, o de los bancos a los intermediarios financieros no bancarios, para que la firma inversionista pueda comprar el bien de capital. Una vez el productor recibe el pago $\left(P_{k}\right)$, puede devolver la financiación inicial $(P)$ al banco. Cabe destacar que de ese modo también puede realizar sus ganancias (iguales a $P_{k-} P_{c}$ ), solucionando así el acertijo de la тсм. Si gasta sus ganancias, esto genera un proceso multiplicador del ingreso adicional por medio del cual se generan más ahorros (fase 2). Estos se canalizan al departamento financiero

${ }_{25}$ Anticipando el ejemplo del apartado siguiente, supongamos que el precio del bien de inversión es $P_{k=} 100$ uc y su costo de producción $P_{c=} 80$ uc (neto de las ganancias normales). Con una propensión marginal a consumir $c=0,8$ se generan 80 uc de ahorros, menos de la financiación final necesaria para financiar la inversión (100 uc).

${ }_{26}$ Como lo ve Febrero: "Si los bancos solo avanzan el costo de producción del capital fijo, ¿de dónde proviene el dinero requerido para monetizar las ganancias del productor de bienes de inversión?” (2008, 118, cursivas añadidas). Ni Davidson (1978 y 1986) ni Bossone (2001) advirtieron el problema.

${ }^{27} \mathrm{Si}$ el banquero de inversiones tuviese dificultades para financiar "la flotación de nuevas emisiones", sostiene Davidson, "podría superar este problema [...] con endeudamiento adicional del sistema bancario" (1986, 105, n. 4). "La flotación de nueva emisión -la colocación del flujo de oferta- es realizada normalmente por intermediarios financieros tales como banqueros de inversión, consorcios de aseguradoras o casas de nueva emisión. Estos intermediarios tienen acceso directo o indirecto (a través de otros intermediarios financieros) a los ahorradores que desean comprar títulos, un acceso que no estaría disponible en forma fácil y directa para la firma inversionista. Cada una de estas entidades financieras también puede esperar normalmente un trato preferencial del sistema bancario e incluso de la autoridad monetaria si se seca inesperadamente la corriente de ahorros en busca de colocación. Este reconocido acceso preventivo a las instituciones que crean dinero es la base última de la liquidez en los mercados financieros" (1978, 323-324). Esto recuerda, por supuesto, el conocido dictamen de Keynes: "Los mercados de inversión pueden llegar a congestionarse por una escasez de efectivo, nunca por una escasez de ahorro. Esta es la más importante de mis conclusiones en este campo" (1937b, 222; 1938, 231-232).

Revista de Economía Institucional, vol. i8, n.o 35, segundo semestre/2oi6, pp. 47-78 
del banco o al intermediario financiero no bancario (el banquero de inversión) que puede pagar el préstamo de corto plazo $^{28}$. Más adelante volveremos al "proceso del doble multiplicador", después de dar un ejemplo que puede ayudar a aclararlo al lector.

“EL CIRCUITO MULTIPLICADOR MONETARIO-PRODUCCIÓN”: UN EJEMPLO DALZIELIANO

Puede ser conveniente dar un ejemplo sumario del funcionamiento del modelo de financiación inicial/final siguiendo los lineamientos que sugiere Dalziel $(1996,315)$, con algunas salvedades que se añaden en el siguiente apartado. Supongamos que una firma inversionista pide en firme un bien de capital que cuesta $P_{k}=100$ uc (unidades de cuenta). Con el pedido en mano, el productor del bien de capital solicita al banco un préstamo de corto plazo (las financiación inicial) para cumplir el pedido (Davidson, 1986). Supongamos que los costos de producción son $P_{c}=80$ uc. El cuadro 1 muestra que la producción del bien de inversión $(\Delta I)$ induce un proceso multiplicador del ingreso $(\Delta Y)$ mediante el cual también aumenta la producción de bienes de consumo $(\Delta C)$. Este es un proceso multiplicador fase 1. Suponiendo una economía cerrada sin administración pública y una propensión a consumir $c=0,8$, el gasto inicial genera una cantidad de ahorros $(\Delta S)$ igual al gasto inicial $P_{c=} 80$ uc. Siguiendo a Dalziel, suponemos que parte de los ahorros generados se invierte a largo plazo $(\Delta S)(90 \%$ en el ejemplo), usualmente a través de intermediarios especializados como los fondos de pensiones, y que el resto se mantiene líquido en una cuenta corriente $(\Delta H)$.

Cuadro 1

Multiplicador keynesiano

(Propensión marginal a financiar el consumo $=0,8$ )

\begin{tabular}{|c|c|c|c|c|c|c|}
\hline Periodos & $\Delta I$ & $\Delta Y$ & $\Delta C$ & $\Delta S$ & $\Delta F$ & $\Delta H$ \\
\hline 1 & 80,0 & $-80,0$ & & & & \\
\hline 2 & & 64,0 & $\rightarrow 64$ & $-16,0$ & $-14,4$ & 1,6 \\
\hline 3 & & 51,2 & $-51,2$ & $-12,8$ & $-11,5$ & 1,3 \\
\hline 4 & & 41,0 & 41,0 & 10,2 & 9,2 & 1,0 \\
\hline 5 & & 32,8 & 32,8 & 8,2 & 72,0 & 8,0 \\
\hline $\begin{array}{l}\cdots \\
\infty\end{array}$ & & 400,0 & 320,0 & 80,0 & 72,0 & 8,0 \\
\hline
\end{tabular}

Obsérvese que la cantidad de ahorro, 80 uc, es menor que la financiación final necesaria para que la firma inversionista financie su inversión

\footnotetext{
${ }^{28}$ Anticipando el ejemplo del apartado siguiente, si el productor gasta $P_{k-} P_{c=}$ 20 uc y $c=0,8$, el ingreso aumenta en 100 uc y los ahorros en 20 uc (llenando la brecha de ahorro de la fase 1; ver n. 26).
} 
de largo plazo; y que parte de estos ahorros (8 uc) se mantiene en forma líquida. Sin embargo, podemos suponer que el banquero de inversión (o el departamento financiero de un banco) aconseja a la firma que supere ambos problemas y le proporciona el préstamo requerido de 100 uc a largo plazo, en parte convirtiendo ahorros de corto plazo en préstamos de largo plazo, y en parte pidiendo a un banco comercial que financie la cantidad necesaria (20 uc) para llenar la brecha del préstamo de largo plazo mediante la creación de dinero endógeno. Así, en esta etapa intermedia la demanda de inversión final es financiada en parte a largo plazo y en parte por crédito/dinero endógeno. Una vez la firma inversionista obtiene su financiamiento de largo plazo, cancela al productor del bien de capital $^{29}$, quien pueden pagar sus deudas a los bancos (80 uc) y gastar sus ganancias $(20 \mathrm{uc})^{30}$. Como resultado de este gasto, se desarrolla un proceso multiplicador similar al del cuadro 1. Este es un proceso multiplicador fase 2. Eventualmente el ingreso aumenta en 100 uc adicionales, de las cuales 20 uc de ahorros son generadas en parte a corto plazo y en parte a largo plazo, recaudadas en última instancia por el banquero de inversión. Por tanto, en esta etapa final se financia toda la demanda de inversión final.

Graziani tenía razón en últimas cuando argumentó que "la inversión encuentra su financiación final en el ahorro" (1994, 83-84; 2003, $71)$, mientras que la financiación inicial o temporal tiene que ver con el inicio de la producción $(1994,82 ; 2003,69)$. También estaba (casi) en lo correcto cuando dijo que "la financiación de la inversión es suministrada por la financiación final y no por anticipos bancarios" $(1990,16)$ y que "el papel de la financiación final es $[. .$.$] hacer$ posible que las firmas cancelen su deuda bancaria” (2003, 69-70). Lo que falta en la brecha entre financiación inicial (crédito de corto plazo) y final (basada en ahorros de largo plazo) es precisamente el proceso multiplicador del ingreso, sin el cual obtenemos resultados confusos; incluido el papel de la financiación final, a veces utilizada para subsanar las pérdidas de las firmas y otras veces para financiar la inversión. La Teoría general, y no el Tratado, es el dominio de un "circuito multiplicador monetario-producción" satisfactorio.

Un detalle poco mencionado se refiere a la igualdad del ahorro y la inversión, que en un examen más atento se mantiene en cualquier etapa del proceso multiplicador y no solo en su terminación. Veamos el periodo 2 del cuadro 1 . Al final de esta etapa los ahorros son de 16 uc y el ingreso generado aún no gastado es de 64 uc. Si consideramos que

29 Si la firma inversionista ha hecho pagos anticipados usará parte del préstamo de largo plazo para pagar préstamos de corto plazo anteriores a los bancos.

${ }^{30}$ Nótese de nuevo la solución al acertijo de las ganancias de la TCM. 
este ingreso aún no gastado es ahorro temporal, el ahorro total es de 80 uc. Como explica Dalziel: "al final de la primera ronda, una parte del gasto de inversión se mantiene como ahorro voluntario [...] mientras que la otra se mantiene como ingreso inducido [...] en anticipo de la segunda ronda" ${ }^{31}(1996,317)$.

\section{Salvedades adicionales}

1. Inicialmente, yo sospechaba que el "proceso del doble multiplicador" era un mecanismo ad hoc. Pero después de más reflexión entendí que no era nada sorprendente porque refleja un aparente acertijo de la teoría de la DE. Por una parte, esta teoría sostiene que la demanda autónoma, financiada por crédito/dinero endógeno, debe preceder a la producción (la visión recibida que comentamos en un apartado anterior); por otra parte, la producción, también financiada por crédito/dinero endógeno (financiación inicial), a menudo precede a la demanda real cuando se emprende con base en la demanda esperada o en pedidos. Así, no hay nada de extraño en encontrar crédito/dinero endógeno en ambas fases: cuando la financiación inicial sea insuficiente para generar financiamiento suficiente para sostener los pagos efectivos de demanda autónoma final ${ }^{32}$, habrá creación adicional de crédito/dinero endógeno para completar la financiación final.

2. E1 lector puede haber observado una asimetría en el ejemplo dalzeliano, en cuanto el productor de bienes de capital usa la financiación inicial para cumplir el pedido mientras que los fabricantes de bienes de consumo producen y distribuyen ingreso solo después de que la demanda monetaria real se ha materializado. Es de presumir que una mayor proporción del producto -incluidos, p. ej., muchos bienes de inversión y de consumo estandarizados- tienda a elaborarse con antelación a la demanda esperada recurriendo a financiación inicial ${ }^{33}$. Esto es consistente con Keynes (1937a y 1937b) y Davidson,

${ }^{31}$ Dalziel usa este resultado para rechazar la afirmación de que "la igualdad de la inversión planeada y el ahorro no ocurre a través del ajuste del ingreso, como afirma el enfoque keynesiano del multiplicador del ingreso" de Moore (1988, 312). Así mismo, Wray descarta el multiplicador del ingreso porque "la inversión y los ahorros son siempre iguales, de modo que su igualdad no puede requerir la operación del proceso multiplicador que toma tiempo" $(1991,960)$. El ejemplo muestra que los ahorros se ajustan a la inversión durante la operación del proceso multiplicador, no solo al final. Una segunda objeción de Wray, según la cual "la historia ignora la financiación inicial del gasto de inversión" es también falaz en opinión de Davidson (1978 y 1996) y de Dalziel (1996).

${ }^{32}$ Insuficiente porque, como se ha mostrado, la financiación inicial solo cubre parte del precio total, p. ej., de un bien de inversión.

${ }^{33}$ La producción anticipada también incluirá la reproducción de bienes intermedios que podemos asumir se heredan del ciclo de producción anterior. Si, 
quienes no limitan el papel de la financiación inicial únicamente a la inversión ${ }^{34}$. No parece que esto introduzca cambios sustanciales porque se puede sostener que, aun en el caso extremo en el que toda la producción se decidiera por adelantado, eso no se puede hacer salvo si se respeta el nivel y la composición del producto final (los niveles y proporciones de $I, C$ y $Z$ ) prescritos por el multiplicador del ingreso ${ }^{35}$. Consideremos el ejemplo del cuadro 1 y supongamos que los capitalistas anticipan la demanda de bienes de inversión y de consumo $(100+400$ uc) mediante la producción y distribución de los salarios antes de los pagos finales. En el cuadro 2 suponemos que los salarios son $4 / 5$ del valor de la producción. Los salarios $(80+320$ uc) se gastan parcialmente $(64+256 \mathrm{uc})$, constituyendo parte de los pagos finales, y se ahorran parcialmente $(16+64 \mathrm{uc})$ y son recaudados por el banquero de inversión (esto se muestra como fase 1 en el cuadro 2). ¿Estamos de regreso al mundo de Say en el que la oferta crea su propia demanda? De ningún modo ${ }^{36}$. Las decisiones de inversión se tomaron independientemente de estos ahorros; de hecho los pedidos de inversión dieron lugar a ahorros, mientras que las ventas esperadas de bienes de consumo eran una proporción exacta de las decisiones de inversión, dictada por el multiplicador keynesiano. Además, como ya vimos, los ahorros generados en la fase 1 no eran suficientes y los banqueros de inversión necesitaron un préstamo de corto plazo complementario de un banco comercial para financiar completamente a los inversionistas. Una vez estos últimos pagaron finalmente los bienes de capital, los productores realizaron sus ganancias y esto generó (fase 2 del cuadro 2) nueva demanda de consumo $(16+64 \mathrm{uc})$ y nuevos ahorros $(4+16 \mathrm{uc})$, de modo que las expectativas de demanda se cumplieron plenamente

por simplicidad, consideramos cada industria (de un solo producto) como una firma integrada verticalmente, la financiación inicial se referirá a la producción de los bienes finales y a la reproducción del capital circulante. Por supuesto, la inversión compleja y los bienes de consumo a la medida no se pueden producir antes de pedidos detallados, pero se necesita financiación para cubrir el periodo de gestación entre el pedido y el pago final. Por definición, los servicios prestados de inmediato no se pueden producir con antelación.

${ }^{34}$ Como señaló Davidson: "el incremento de la demanda inducido por los bienes de consumo requerirá que los productores de bienes de consumo financien la inversión adicional en capital de trabajo, la cual, por simplicidad, se puede suponer que es financiada por préstamos adicionales de corto plazo de los bancos" (1978, 271-272).

${ }^{35}$ Por supuesto, el análisis de estabilidad debe mostrar que hay mecanismos de mercado por medio de los cuales el nivel y la composición de la demanda esperada y de la capacidad tienden a converger al nivel de equilibrio (para el caso del supermultiplicador, ver, p. ej., Freitas y Serrano, 2015).

${ }^{36}$ Ver el apartado "La financiación de Keynes". 
y el banquero de inversión pudo recaudar los ahorros adicionales y pagar el préstamo de corto plazo al banco.

En esta narración perdemos algo de la imagen secuencial del multiplicador del cuadro 1 en la que el consumo es inducido. Aquí todo el salario-consumo se financia con préstamos bancarios, pero a diferencia del consumo autónomo, es inducido por la demanda esperada. Aunque la dinámica del multiplicador esté oculta, está allí. De hecho, el cuadro 2 puede describir una situación tranquila en la que las expectativas se han ajustado a un patrón recurrente de DA, que sin embargo comenzó en algún momento del pasado con pedidos de inversión inesperados seguidos de una secuencia de eventos como los del cuadro 1. (Las diferencias secundarias con el cuadro 1 son que todas las ganancias se realizan en la fase 2 mientras que todos los salarios se pagan en la fase 1 , y el intervalo de tiempo en el que maduran los flujos del cuadro 2 es quizá menor que el del cuadro 1).

Cuadro 2

Todo el producto se elabora con antelación

\begin{tabular}{|c|c|c|c|c|c|c|c|c|c|}
\hline \multicolumn{3}{|c|}{$\begin{array}{c}\text { Demanda esperada } \\
\text { y producción } \\
\text { anticipada } \\
\end{array}$} & \multirow[b]{2}{*}{ Salarios } & \multirow[b]{2}{*}{$\begin{array}{l}\text { Demanda } \\
\text { real de } \\
\text { consumo } \\
\text { (fase } 1 \text { ) }\end{array}$} & \multirow[b]{2}{*}{$\begin{array}{l}\text { Ahorro } \\
\text { (fase 1) }\end{array}$} & \multirow[b]{2}{*}{$\begin{array}{l}\text { Demanda } \\
\text { real de } \\
\text { inversión }\end{array}$} & \multirow[b]{2}{*}{ Ganancias } & \multirow[b]{2}{*}{$\begin{array}{l}\text { Demanda } \\
\text { real de } \\
\text { consumo } \\
\text { (fase 2) }\end{array}$} & \multirow[b]{2}{*}{$\begin{array}{l}\text { Ahorro } \\
\text { (fase 2) }\end{array}$} \\
\hline & $\begin{array}{l}\text { Bienes de } \\
\text { inversión }\end{array}$ & $\begin{array}{l}\text { Bienes de } \\
\text { consumo }\end{array}$ & & & & & & & \\
\hline & 100 & 0 & 80 & 64 & 16 & 100 & 20 & 16 & 4 \\
\hline & 0 & 400 & 320 & 256 & 64 & 0 & 80 & 64 & 16 \\
\hline Total & 100 & 400 & 400 & 320 & 80 & 100 & 100 & 80 & 20 \\
\hline
\end{tabular}

3. Una cuestión adicional se refiere a las utilidades retenidas o financiación interna final como posible alternativa a la financiación externa final para financiar la inversión, sin duda un importante canal, si bien no exclusivo, para financiarla. A este respecto cabe señalar que las decisiones de inversión que llevan a decisiones de producción de bienes de capital pagadas con financiación inicial -en el corto plazo, mediante un uso más completo de la capacidad y, en el largo plazo, mediante la creación de nueva capacidad-son las que determinan los ahorros (incluidas las utilidades retenidas) y no al contrario ( $\mathrm{p}$. ej., Garegnani, 2015, 121, n. 22). Así, la financiación interna debe ser lógicamente una forma en la que la financiación final se presenta a si misma. Con respecto a los cuadros 1 y 2 , el ahorro generado por el proceso multiplicador también puede consistir en utilidades retenidas por la firma inversionista utilizadas para financiar inversión y reducir la necesidad de financiamiento final externo para saldar el pago final de los bienes de capital. Conforme a la lógica keynesiana, aunque la 
inversión sea financiada por utilidades/ahorros retenidos (además de ahorros externos), fue un pedido inicial de bienes de capital financiado por el fondo rotatorio (financiación inicial) el que generó, a través del multiplicador keynesiano, esas utilidades/ahorros.

4. En el espíritu de Davidson y Dalziel, nuestro ejemplo relacionó la financiación inicial y final y el análisis del multiplicador con la inversión como variable independiente. En el análisis del supermultiplicador, la inversión es un componente inducido de la DA junto con el consumo. $\mathrm{El}$ consumo autónomo es en cambio un componente autónomo en los análisis del multiplicador y del supermultiplicador. Keynes da el ejemplo del hombre que hace el pedido de una casa ${ }^{37}$, a través de una sociedad constructora:

No es su promesa la que proporciona la financiación requerida por el constructor sino los recursos que la sociedad constructora obtiene del conjunto de recursos líquidos [...] bien sean efectivo aportado por el empresario o nuevo efectivo proporcionado por los bancos, pagando un interés por esos recursos (1937a, 218-219).

Mutatis mutandis, este caso se asemeja al del cuadro 1. La sociedad constructora, después de obtener los fondos mediante un préstamo bancario (crédito/dinero endógeno creado), anticipa $P_{c}=80$ uc de costos de producción (netos de beneficios) al constructor. El precio final es $P_{k}=100 \mathrm{uc}^{38}$.

Tenemos un proceso multiplicador fase 1 al final del cual parte del sector privado mantiene un ahorro de 80 uc que está prestando, a través de intermediarios financieros, a otra parte del sector privado (la persona que compra la casa). Una vez la casa está lista, la sociedad constructora necesita un segundo préstamo bancario (20 uc) (creado endógenamente) para cubrir el precio total que el comprador debe pagar. Una vez el constructor gasta sus ganancias (20 uc), se desarrolla un proceso multiplicador fase 2 , en cuya parte más alta los ahorros aumentan en 20 uc adicionales y se canalizan a la sociedad constructora a largo plazo, la cual puede entonces cancelar el segundo préstamo bancario. La diferencia con respecto al cuadro 1 es que el ahorro neto final del sector privado en su conjunto es nulo porque los ahorros (100 uc) son compensados totalmente por el consumo autónomo $\left(P_{k}=100\right.$ uc), el cual es un acto de desahorro.

Por último, tomando en cuenta las exportaciones, las firmas del sector exportador, en vista de los pedidos extranjeros esperados, po-

37 E1 cual es gasto autónomo que no crea capacidad.

${ }^{38}$ También en este caso podíamos haber supuesto que el constructor consigue parte de la financiación inicial en un banco y parte como pago anticipado de la sociedad constructora. 
drían financiar la producción de exportaciones mediante préstamos de corto plazo (financiación inicial). La producción genera ahorros domésticos que se prestan a los bancos extranjeros que financian las importaciones. Una vez se venden las exportaciones, la financiación inicial es eventualmente reembolsada ${ }^{39}$. El endeudamiento externo neto es la contraparte financiera del superávit neto en cuenta corriente de la economía exportadora.

Los casos del consumo autónomo y de las exportaciones netas son interesantes porque están asociados a la posibilidad de que los hogares y los países, respectivamente, acumulen deuda y así provoquen crisis financieras. Vienen a la mente los ejemplos de crecimiento basado en deuda de los hogares en Estados Unidos durante la era de la gran moderación y del comportamiento mercantilista alemán como causa de la crisis de la eurozona.

\section{COMENTARIOS FINALES}

Este artículo sugiere una manera de integrar las teorías keynesianas del multiplicador y del supermultiplicador a la visión del dinero endógeno, la teoría de la financiación de Keynes y la тсM, prestando particular atención a la visión del circuito monetario de Graziani. Se seleccionó el enfoque clásico-keynesiano del supermultiplicador como el medio más prometedor para extender al largo plazo la propuesta keynesiana de la independencia entre inversión y capacidad de ahorro. En este enfoque los componentes autónomos de la DA impulsan la producción y la acumulación. Los aspectos financieros de este enfoque aún están muy poco desarrollados. E1 artículo es un paso hacia la integración del interés de la тсм en el dinero endógeno y la financiación y del interés clásico-keynesiano en la teoría del (super)multiplicador. Es también un paso para reconciliar la preocupación de Graziani por la oferta y la financiación inicial de la producción con el interés de las teorías heterodoxas orientadas a la demanda en la financiación final de la demanda autónoma.

Si la producción de bienes de consumo y de inversión se decide con base en la demanda esperada o en órdenes de compra, es lógicamente anterior a los pagos. Esto crea la necesidad de financiación

\footnotetext{
39 También en este caso podemos añadir todas las complicaciones que queramos. Por ejemplo, que la financiación inicial solo cubra los costos de producción de las exportaciones pero no las ganancias. Los ahorros prestados a clientes extranjeros serán entonces menores que el precio de venta total. Los bancos comerciales del país exportador o importador llenarán la brecha creando un préstamo adicional de crédito/dinero endógeno para el cliente. Así los exportadores monetizan sus ganancias dando lugar a un proceso multiplicador fase 2 que genera un segundo préstamo basado en el ahorro al país importador.
} 
inicial, creada endógenamente por los bancos comerciales, para llevar a cabo la producción. Siguiendo las sugerencias de Davidson, Dalziel y otros autores, este artículo muestra que la financiación inicial, a través del (super)multiplicador del ingreso, es la que genera los ingresos por medio de los cuales la demanda esperada y las órdenes de compra se convierten en gasto efectivo: directamente en el caso del consumo inducido o indirectamente en el caso de la inversión y el gasto autónomos financiados por los ahorros generados por el mismo proceso multiplicador del ingreso. A este respecto, el artículo considera insatisfactoria la тсм de Graziani precisamente porque omite (o incluso rechaza) el análisis del (super)multiplicador del ingreso, el cual es justamente el nexo entre financiación inicial y final.

Se examinaron varias complicaciones. Por ejemplo, puesto que la financiación inicial solo cubre los costos de producción del bien de inversión, sin incluir las ganancias de los productores de bienes de capital, los ahorros generados son menores que la financiación final, de largo plazo, requerida por la firma inversionista. Por tanto, podría ser necesaria una creación adicional de crédito/dinero endógeno final para financiar totalmente la inversión deseada. Esto permite resolver el acertijo de la realización de las ganancias de la тсм. Una vez todo esto se completa, todos los sujetos que han recibido financiación inicial pagan sus deudas, quizá solicitando la renovación de las líneas de crédito (o su ampliación, en una economía en progreso) en vista del siguiente periodo de producción. La financiación se asemeja entonces a un fondo rotatorio keynesiano, que crece en una economía en expansión. Empleando el multiplicador del ingreso, que la тсм de Graziani subvalora, probamos rigurosamente la idea de Graziani de que la financiación inicial pertenece a la producción mientras que la demanda de inversión se financia con ahorros, incluso resolviendo el acertijo de las ganancias de la тсм. Este enfoque es recordado sintéticamente por Lavoie (2015b, 8). Aunque se ocupa principalmente del caso estándar del multiplicador keynesiano, el artículo da algunos pasos para extender el análisis a otros componentes autónomos del gasto privado conforme al enfoque del supermultiplicador.

\section{REFERENCIAS BIBLIOGRÁFICAS}

1. Allain, O. "Tackling the instability of growth: A Kaleckian-Harrodian model with an autonomous expenditure component", Cambridge Journal Economics 39, 5, 2015, pp. 1351-1371.

2. Arestis, P. y M. Sawyers, eds. A handbook of alternative monetary economics, Cheltenham, Edward Elgar, 2006. 
3. Barba, A. y M. Pivetti. "Rising household debt: Its causes and macroeconomic implications - A long-period analysis", Cambridge Journal of Economics 33, 1, 2009, pp. 113-137.

4. Bertocco, G. "The role of credit in a Keynesian monetary economy", Review of Political Economy 17, 4, 2005, pp. 489-511.

5. Bertocco, G. "Global saving glut and housing bubble: A critical analysis", Economia Politica 31, 2, 2014, pp. 195-218.

6. Bindseil U. y P. J. Konig, "Basil J. Moore's horizontalists and verticalists: An appraisal 25 years later", Review of Keynesian Economics 1, 4, 2013, pp. 383-390.

7. Borio, C. "The international monetary and financial system: Its Achilles heel and what to do about it", BIs working papers 456, 2014.

8. Bossone, B. "Circuit theory and finance", Journal of Banking Eं Finance 25, 2001, pp. 857-890.

9. Bougrine, H. y M. Seccareccia, "Money, taxes, public spending, and the State within a circuitist approach", International Journal of Political Economy 32, 3, 2004, pp. 58-79.

10. Cesaratto, S. "Harmonic and conflict views in international economic relations: A Sraffian view", E. S. Levrero et al., eds., Sraffa and the reconstruction of economic theory, vol. II, Londres, Palgrave Macmillan, 2013a.

11. Cesaratto, S. "The implications of TARGET2 in the European balance of payment crisis and beyond", European Journal of Economics and Economic Policies: Intervention 10, 3, 2013b, pp. 359-382.

12. Cesaratto, S. "Neo-Kaleckian and Sraffian controversies on the theory of accumulation", Review of Political Economy 27, 2, 2015, pp. 154-182.

13. Cesaratto, S. "The State spends first: Logic, facts, fictions, open questions", Journal of Post Keynesian Economics 39, 2016a, pp. 445-471.

14. Cesaratto, S. "When Robertson was Keynesian and Keynes Robertsonian: A discussion between D. H. R. and J. M. K. in the early 1930s and the problems with the monetary circuit theory. A note", Universidad de Siena, Quaderni del Dipartimento di Economia Politica e Statistica 732, 2016b.

15. Cesaratto, S. y G. Mongiovi. "Pierangelo Garegnani, the classical surplus approach and demand-led growth: Introduction to the symposium", Review of Political Economy 27, 2, 2015, pp. 103-110.

16. Chick, V. "Money and effective demand", J. Smithin, ed., What is money, Londres, Routledge, 2000.

17. Dalziel, P. C. "The Keynesian multiplier, liquidity preference, and endogenous money”, Journal of Post Keynesian Economics 18, 3, 1996, pp. 311-331.

18. Dalziel, P. C. y G. C. Harcourt. “A note on 'Mr Meade's relation' and international capital movements", Cambridge Journal of Economics 21, 5, 1997, pp. 621-631.

19. Davidson, P. Money and the real world, 2nd ed., Londres, Macmillan, 1978.

20. Davidson, P. "Finance, funding, saving, and investment", Journal of Post Keynesian Economics 9, 1, 1986, pp. 101-110. 
21. Febrero, E. "E1 circuito monetario", documentos de trabajo, Facultad de Ciencias Económicas y Empresariales, serie 1, 10, 2001, [https:// www.researchgate.net/profile/Eladio_Febrero/publications/].

22. Febrero, E. "The monetization of profits in a monetary circuit framework", Review of Political Economy 20, 1, 2008, pp. 111-125.

23. Febrero, E. y F. Bermejo. "Spain during the great recession", O. Dejuán et al., eds., Post-Keynesian views of the crisis and its remedies, Londres, Routledge, 2013.

24. Febrero, E. y J. Uxo. "Understanding TARget2 imbalances from an endogenous money view”, Departamento de Economía y Finanzas, Universidad de Castilla-La Mancha, Dt/DAef 2013/2, 2013.

25. Fontana, G. y M. Sawyer. "Towards Post-Keynesian ecological macroeconomics", Ecological Economics 121, 2016, pp. 186-195.

26. Freitas, F. y F. Serrano. "Growth rate and level effects, the adjustment of capacity to demand and the Sraffian supermultiplier", Review of Political Economy 27, 3, 2015, pp. 258-281.

27. Garegnani, P. "The problem of effective demand in Italian economic development: On the factors that determine the volume of investment", Review of Political Economy 27, 2, 2015, pp. 111-133; trad. de la segunda parte de Il problema della domanda effettiva nello sviluppo economico italiano, Roma, svimez, 1962.

28. Gnos, C. "French circuit theory", P. Arestis y M. Sawyer, eds., $A$ handbook of alternative monetary economics, Cheltenham, Edward E1gar, 2006.

29. Gnos, C. y L.-P. Rochon. "Money creation and the State", International Journal of Political Economy 32, 3, 2004, pp. 41-57.

30. Graziani, A. "The theory of the monetary circuit", Economies et Sociétés 24, 6, 1990, pp. 7-36.

31. Graziani, A. La teoria monetaria della produzione, Florencia, Banca Popolare dell'Etruria e del Lazio, Studi e ricerche, 1994.

32. Graziani, A. The monetary theory of production, Cambridge, uk, Cambridge University Press, 2003.

33. Hein, E. "Finance-dominated capitalism, re-distribution, household debt and financial fragility in a Kaleckian distribution and growth model", PSL Quarterly Review 65, 260, 2012, pp. 11-51.

34. Hicks, J. R. A contribution to the theory of the trade cycle, Oxford, uK, Clarendon Press, 1950.

35. Jakab, Z. y M. Kumhof. "Banks are not intermediaries of loanable funds - And why this matters", Bank of England, working paper 529, 2015.

36. Keynes, J. M. 1930, A treatise on money, vol. I, The pure theory of money, reimpreso en The collected writings of John Maynard Keynes, D. Moggridge, ed., vol. v, part I, Londres, Macmillan, 1971.

37. Keynes, J. M. The general theory of employment, interest and money, Londres, Macmillan, 1936.

38. Keynes, J. M. "Alternative theories of the rate of interest", Economic Journal 47, 1937a, pp. 241-52; reimpreso en D. Moggridge, ed., The collected writings of J. M. Keynes, vol. xiv, part II, Londres, Macmillan, 1973. 
39. Keynes, J. M. “The 'ex ante' theory of the rate of interest”, Economic Journal 47, 1937b, pp. 663-69; reimpreso en D. Moggridge, ed., The collected writings of J. M. Keynes, vol. xIv, part II, Londres, Macmillan, 1973.

40. Keynes, J. M. "Mr Keynes and 'Finance”, Economic Journal 48, 1938, pp. 318-322; reimpreso en D. Moggridge, ed., The collected writings of J. M. Keynes, vol. xiv, part II, Londres, Macmillan, 1973.

41. Lavoie, M. Foundations of Post-Keynesian economic analysis, Aldershot, Edward Elgar, 1992.

42. Lavoie, M. "A primer in endogenous credit-money", L. P. Rohon y S. Rossi, eds., Modern theories of money. The nature and role of money in capitalist economies, Cheltenham, Edward Elgar, 2005.

43. Lavoie, L. "The monetary and fiscal nexus of neo-Chartalism: A friendly critical look", Journal of Economic Issues 47, 1, 2013, pp. 1-32.

44. Lavoie, M. "Convergence towards the normal rate of capacity utilization in neo- Kaleckian models: The role of non-capacity creating autonomous expenditures", Metroeconomica 67 1, 2015a, pp. 172-201.

45. Lavoie, M. "What post-Keynesian economics has brought to an understanding of the global financial crisis", Progressive Economics Forum at the Annual Conference of the Canadian Economics Association, Toronto, mayo de 2015b, [www.boeckler.de/ pdf/v_2015_10_24_lavoie.pdf].

46. Lazzarini, A. 2011, Revisiting the Cambridge capital theory controversies, Pavía, Pavia University Press.

47. McLeay, M.; R. Amar y T. Ryland. "Money creation in the modern economy", Bank of England, Quarterly Bulletin, 54, 1, 2014, pp. 1-14.

48. Moore, B. J. "Unpacking the Post Keynesian black box: Bank lending and the money supply", Journal of Post Keynesian Economics 5, 4, 1983, pp. 537-556.

49. Moore, B. J. Horizontalists and verticalists. The macroeconomics of credit money, Cambridge, uк, Cambridge University Press, 1988.

50. Pariboni, R. "Autonomous consumption, household debt and growth: A supermultiplier based analysis", R. Paribonei, Autonomous demand and capital accumulation: Three essays on heterodox growth theory, tesis de doctorado, Department de Economía Política y Estadística, Universidad de Siena, 2015.

51. Passarella V., M. y M. Sawyer. "Financialisation in the circuit", FEssud working paper series 18, 2014.

52. Pivetti, M. "Money endogeneity and monetary non-neutrality: A Sraffian perspective”, L.-P. Rochon y M. Vernengo, eds., Credit, interest rates and the open economy, Cheltenham, Edward Elgar, 2001.

53. Realfonzo, R. "Italian circuitist approach", P. Arestis y M. Sawyer, eds., The handbook of alternative monetary economics, Cheltenham, Edward Elgar, 2006.

54. Rochon, L.-P. "The creation and circulation of endogenous money: A circuit dynamique approach", Journal of Economic Issues 33, 1, 1999, pp. $1-21$.

55. Rochon, L.-P. "On money and endogenous money: Post Keynesian and circulation approaches”, L.-P. Rochon y S. Rossi, eds., Modern 
theories of money: The nature and role of money in capitalist economies, Cheltenham, Edward Elgar, 2003.

56. Rochon, L.-P. "The existence of monetary profits within the monetary circuit”, G. Fontana y R. Realfonzo, eds., The monetary theory of production, Londres, Palgrave Macmillan, 2005.

57. Rochon, L.-P. y S. Rossi, eds. Modern theories of money: The nature and role of money in capitalist economies, Cheltenham, Edward Elgar, 2003.

58. Sawyer, M. "Bank-based versus market-based financial systems: A critique of the dichotomy", FESSUD working paper series 19, 2014.

59. Smithin, J. Money, enterprise and income distribution: Towards a macroeconomic theory of capitalism, Oxon, Routledge, 2009.

60. Terzi, A. Economia monetaria, Milán, Educatt, 2012.

61. Wicksell, K. Lectures on Political Economy, vol. II, Money, trad. de la 3. ${ }^{a}$ edición sueca de 1929, Londres, Routledge and Kegan Paul, 1935,

62. Wray, L. R. "Saving, profits, and speculation in capitalist economies", Journal of Economic Issues 25, 4, 1991, pp. 951-975.

63. Wray, L. R. Understanding modern money, Cheltenham, Edward Elgar, 1998.

64. Wray, L. R. “The s\&P downgrade: Much ado about nothing because a sovereign government cannot go bankrupt", 2011. [http://wallstreetpit. com/71874-the-sp-downgrade-much-ado-about-nothing-becausea-sovereign-government-cannot-go-bankrupt/]. 